\title{
Effect of dietary nucleotides on small intestinal repair after diarrhoea. Histological and ultrastructural changes
}

\author{
J Bueno, M Torres, A Almendros, R Carmona, M C Nuñez, A Rios, A Gil
}

\begin{abstract}
The effects of specific nutrients on intestinal maturation and repair after injury are practically unknown. The purpose of this work was to study the effects of dietary nucleotides on the repair of the intestinal mucosa after chronic diarrhoea induced by a lactose enriched diet in the weanling rat. One group of weanling rats was fed with a standard semipurified diet (control group), and another group was fed with the same diet containing lactose as the only soluble carbohydrate (lactose group). After 14 days the lactose group was allowed to recover for four weeks with the control diet (lactose-control group) or with the control diet supplemented with AMP, GMP, IMP, CMP, and UMP 50 $\mathrm{mg} / 100 \mathrm{~g}$ each (lactose-nucleotide group). The control group was divided into two subgroups, which were fed with the control diet and the nucleotide supplemented diet for the same period (control-control group and control-nucleotide group). The lactose diet induced diarrhoea after 24 hours of feeding. Two weeks later there were changes in intestinal structure with loss of enterocyte microvillar surface, significant lymphocyte infiltration, supranuclear cytoplasmic vesiculation, decreased number of goblet cells, and enlarged mitochondria with low density and few cristae. After recovery from diarrhoea, animals fed the nucleotide enriched diet showed an intestinal histology and ultrastructure closer to that of the normal control group. Mitochondrial ultrastructure was closer to normal in comparison with the lactose-control diet group. In this second group the number of goblet cells as well as the villous height/crypt depth ratio was reduced and the number of intraepithelial lymphocytes increased compared with the nucleotide supplemented group. These results suggest that dietary nucleotides may be important nutrients for intestinal repair. (Gut 1994; 35: 926-933)
\end{abstract}

Early infancy is a period of rapid overall growth and development. During early postnatal life the infant is particularly susceptible to intestinal injury. Chronic diarrhoea in infancy is characterised by prolonged small intestinal mucosal injury, which is usually accompanied by malabsorption of nutrients and infection. ${ }^{1-5}$ One of the most important disorders associated with protracted diarrhoea and villous atrophy in infancy is secondary disaccharide malabsorption. ${ }^{67}$

Partial villous atrophy with considerable patchiness is seen in mucosal specimens obtained from patients with chronic diarrhoea. ${ }^{24}$ In addition, elongation of crypts, increased lymphocyte infiltration, and a high number of plasma cells and macrophages can be seen. ${ }^{489}$ Moreover, there is a vacuolisation of the cytoplasm with increased multivesicular bodies and the cell space is occupied by large and abnormal mitochondria. ${ }^{248-10}$ Deficient enzymatic activities as well as low protein: DNA cell ratios can be seen as a result of chronic diarrhoea or malnutrition. ${ }^{1} 1112$

The role of specific nutrients in the development of the gastrointestinal tract and repair after injury is not fully understood. The absence of enteral nutrients during weaning results in striking inhibition of intestinal growth, and development ${ }^{13}$ and refeeding seems to stimulate the renewal of the absorptive epithelium. ${ }^{14} 15$

There are a number of factors that participate in the regulation of the renewal of the absorptive epithelium and in the repair of the epithelium under abnormal conditions. ${ }^{9}$ Nitrogen containing nutrients seem to be of great importance for gut development. At weaning protein modulates the ontogenic changes in tissue DNA synthesis and plays a part in completing the growth of the rat's gastrointestinal tract. ${ }^{16}$ Recently, dietary nucleotides have been shown to be important for gut development and repair after injury. Uauy and Stringel ${ }^{17}$ have reported that intestinal disaccharidase activities are increased in rats during development by dietary nucleotides and we have recently shown that DNA, lactase, sucrase, and maltase activities increase in animals treated with a supplemented nucleotide diet after chronic diarrhoea. ${ }^{18}$

\begin{tabular}{lrlr}
$\begin{array}{l}\text { TABLE I } \\
\text { of food) }\end{array}$ & Composition of the control diet (grams per $100 \mathrm{~g}$ \\
\hline Ingredient & $\mathrm{g}$ & Chemical composition & $\mathrm{g}$ \\
\hline Casein & $16 \cdot 7$ & Protein & 15 \\
Corn starch & $50 \cdot 3$ & Carbohydrates & 70 \\
Sugar & $15 \cdot 0$ & Fat & 10 \\
Cellulose & $5 \cdot 0$ & Minerals & 2 \\
Soy oil & $10 \cdot 0$ & Moisture & 3 \\
DL-Methionine & $0 \cdot 3$ & & \\
Mineral and vitamin mix & $2 \cdot 7$ & & \\
\hline
\end{tabular}

Nucleotide supplemented diets were obtained by adding $50 \mathrm{mg}$ of each of the following nucleotides to $100 \mathrm{~g}$ of the control diet: AMP, GMP, IMP, CMP, and UMP. Lactose diet was obtained by using lactose instead of corn starch as a according to the nutritional requirements of Wistar rats. 

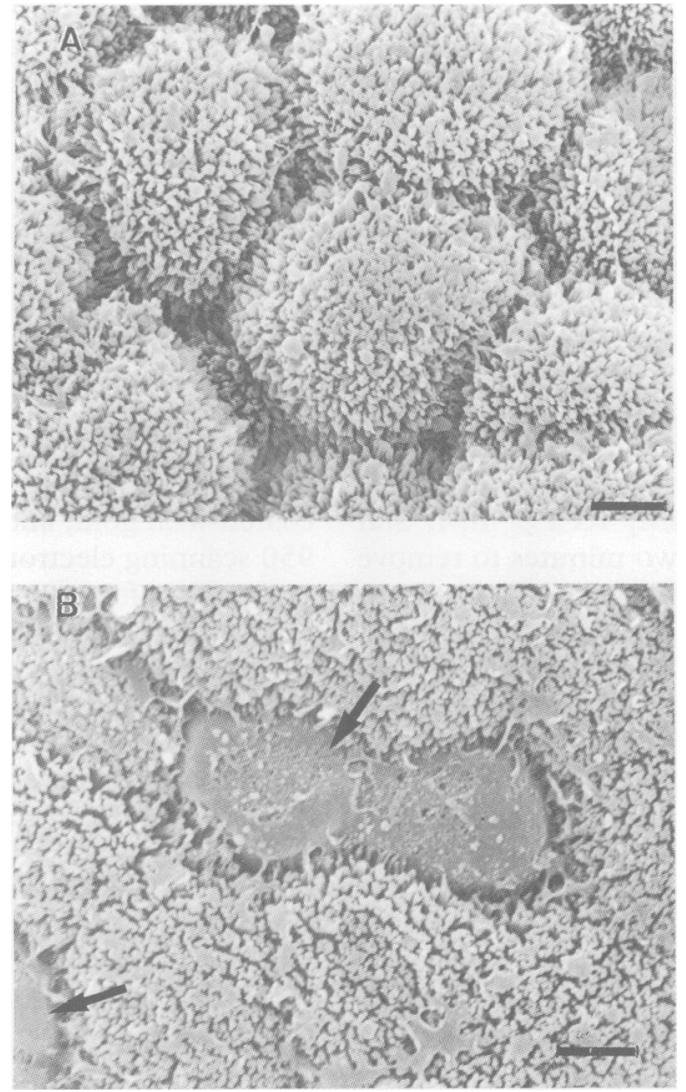

Figure 1: Scanning electron micrographs of the apical surface of duodenal epithelium from weaned rats fed a semipurified synthetic control diet $(A)$ and from weaned rats fed a lactose enriched diet that produced protracted diarrhoea $(B)$. (A): The enterocytes present clearly delimited cell borders, convex apical surface, and well developed microvilli and glycocalix; (B): extended regions with damage to the microvilli and a loss of delimitation of cellular areas can be seen (arrows). Bar: $2 \mu \mathrm{m}$ (original magnification $\times 12500$ ).

The aim of this paper was to study the histological changes of the intestinal mucosa in weanling rats with protracted diarrhoea and malnutrition associated to a lactose enriched diet and the effects of feeding a nucleotide supplemented diet during recovery on small bowel structure, enterocyte morphometry, and intestinal ultrastructure.

\section{Methods}

ANIMALS

Wistar rats at weaning (21 days) supplied by the Servicio de Animales of the University of Granada, Spain, were used. Animals were kept at $22 \pm 1^{\circ} \mathrm{C}$ on a 12 hour light-dark cycle. Animals were housed in individual cages and the actual food eaten by each animal, as well as the weight, was recorded daily. The cages were made of stainless steel and had a wired floor mounted on a separate plastic container, which prevented animals eating their own faeces and wood shavings. A group of 18 rats was fed ad libitum a semipurified synthetic diet containing $15 \%$ protein (control group). The nucleotide content of the control diet was negligible as determined by high performance liquid chromatography. A second group of 18 rats was weaned on a similar diet in which the soluble carbohydrate (corn starch) was substituted by lactose as the only carbohydrate (lactose group). Rats fed with this diet developed diarrhoea after one day of feeding as previously described. ${ }^{18}$ After two weeks six animals of each group, control and lactose, were killed. Animals remaining in the lactose and control groups were divided into two subgroups of six rats each, which were fed for four weeks either the control diet (lactosecontrol subgroup, and control-control subgroup) or the same diet supplemented with 50 $\mathrm{mg}$ of each of the following nucleotides: AMP, GMP, IMP, CMP, and UMP per $100 \mathrm{~g}$ of diet (lactose-nucleotide subgroup and control-nucleotide subgroup). Table I shows the composition of the diets. All animals in subgroups control-control, control-nucleotide, lactose-control, and lactosenucleotide were killed after four weeks. Rats fed the lactose diet had an average daily weight decrease of $1.59 \pm 0.54 \mathrm{~g}$; animals who recovered (lactose-control and lactosenucleotide groups) as well as control rats (control-control and control-nucleotide groups) showed an average daily weight increase (mean (SD)) of $6.70(0.42) \mathrm{g}, 6.25$ $(0.31) \mathrm{g}, 6.36(0.26) \mathrm{g}$, and $6.39(0.20) \mathrm{g}$, respectively. The protocol was approved by the animal care and use committee of the University of Granada.
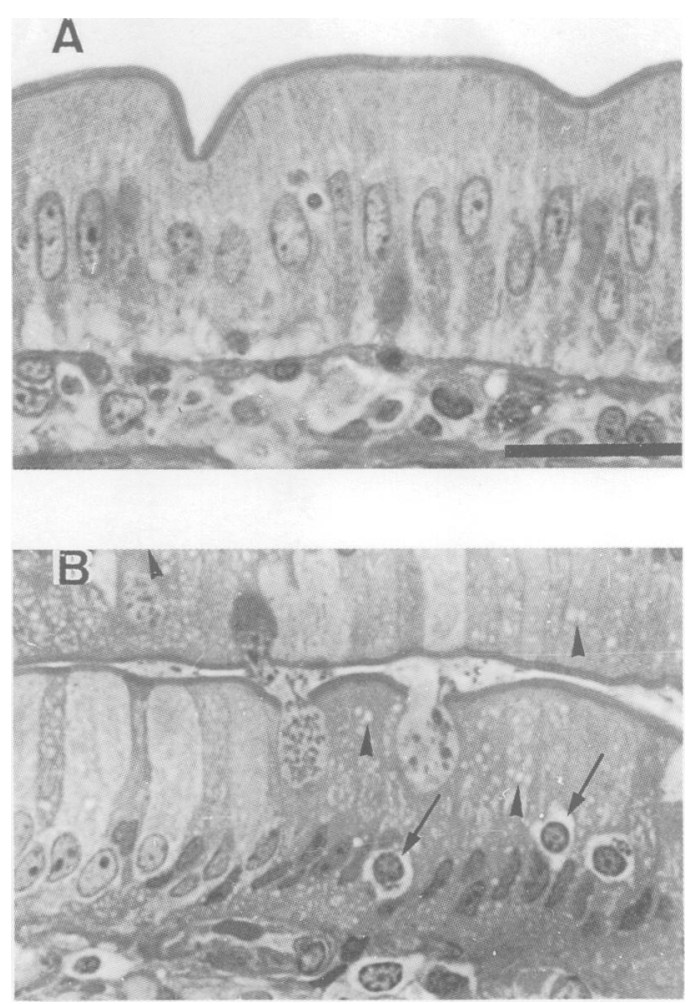

Figure 2: Light micrographs of duodenal epithelium from weaned rats fed a control semipurified diet $(A)$ and from weaned rats fed a lactose enriched diet that caused protracted diarrhoea $(B)$. $(A)$ : The epithelium presents a well developed brush border with no vesiculation; $(B):$ the epithelium appears uniformly vesiculated (arrow heads) and with lymphocyte infiltration (arrows). Several enterocytes show lysis as they detach themselves from adjacent viable enterocytes. Bar: $25 \mu \mathrm{m}$ (original magnification $\times 850$ ) 
TISSUE PROCESSING FOR LIGHT AND ELECTRON MICROSCOPIC ANALYSIS

The animals were weighed and decapitated between 9 and 11 am because the small intestine shows circadian differences in morphology and activity. The small intestine from the pylorus to the ileocaecal valve was removed and the segment between the pylorus and the angle of Treitz was considered as duodenum. The rest of the intestine was divided into two equal segments; the proximal part was considered as jejunum and the distal part as ileum. The intestinal lumen for each segment was perfused with isotonic buffered saline solution $(\mathrm{Na} \mathrm{Cl} 120 \mathrm{mM}, \mathrm{KCl} 5 \mathrm{mM}$, and $\mathrm{NaH} \mathrm{CO} 23 \mathrm{mM}$ ) for two minutes to remove debris. Every segment was excised on three roughly equal size parts and three small sections from each part were obtained thus making a total of nine samples from each segment and animal. A portion of the mucosal sample was processed for light microscopy study, another one for scanning electron microscopy, and the last section was used for transmission electron microscopy and for structural examination on semithin sections under light microscopy.

Samples for light microscopy were immediately fixed in Bouin's solution. Fixed tissues
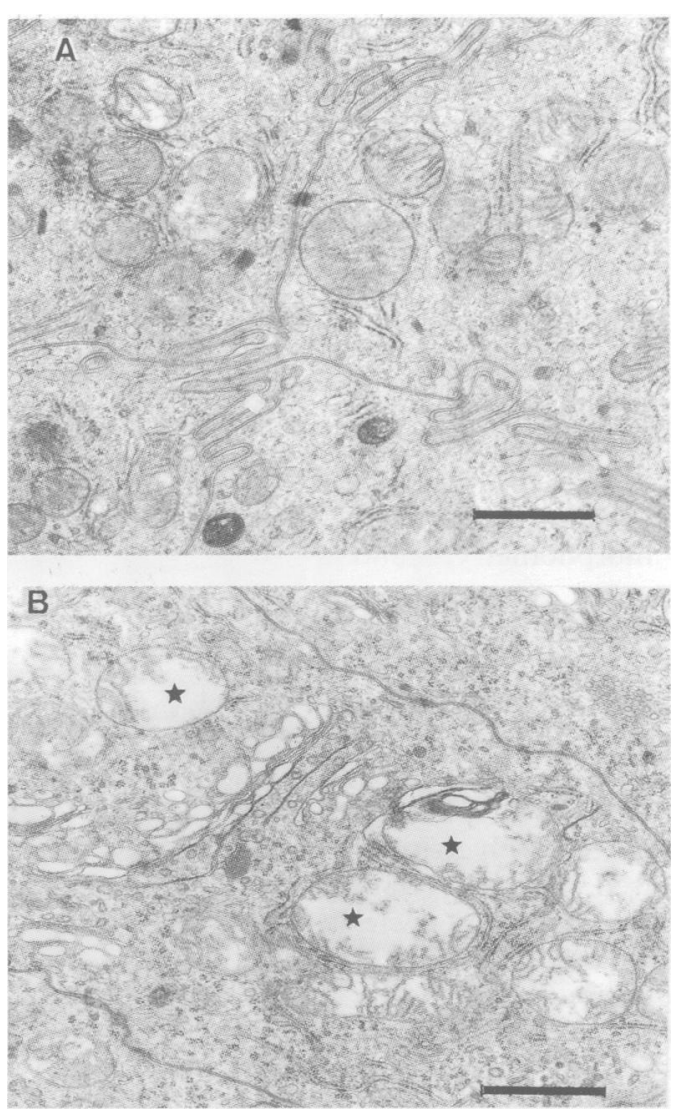

Figure 3: Transmission electron micrographs of enterocyte cytoplasm from weaned rats fed a control semipurified diet (A) and from weaned rats fed a lactose enriched diet that caused protracted diarrhoea (B). (A): Mitochondria show a dense matrix; endoplasmic reticulum and dense bodies can be seen in well defined cellular territories; $(B)$ : mitochondria have lost their inner matrix density and show a few cristae (stars); a dilated endoplasmic reticulum and Golgy apparatus can also be seen. Bar: $1 \mathrm{\mu m}$ (original magnification $\times 30$ 000). were then carefully oriented and embedded in paraffin wax. For each specimen at least 10 sections of $10 \mu \mathrm{m}$ thickness were obtained, the mucosa was cut perpendicularly to the muscularis mucosa, and stained with haematoxylin and eosin for histological evaluation. For the scanning electron microscopy study fresh intestinal segments were excised longitudinally into small pieces, which were fixed in $2.5 \%$ glutaraldehyde and $2.5 \%$ paraformaldehyde in $0 \cdot 1 \mathrm{M}$ sodium cacodylate buffer, $350 \operatorname{mos} \mathrm{M}$, pH 7. Samples were then dried to Anderson's critical point ${ }^{19}$ and subsequently attached to planchets with the mucosa facing upwards, coated with gold, and examined under a Zeiss 950 scanning electron microscope.

Samples for examination by transmission electron microscopy were fixed as for scanning electron microscopy and subsequently fixed in a solution of $2 \%$ osmium tetroxide in $0.1 \mathrm{M}$ sodium cacodylate buffer. After acetone dehydration, samples were embedded in Spurr resin. ${ }^{20}$ Two $\mu \mathrm{m}$ semithin sections were stained in toluidine blue for light microscopic observation and 500-700 $\mu \mathrm{m}$ ultrathin sections with subsequent contrast in uranyl acetate and lead citrate according to Reynolds ${ }^{21}$ were examined for ultrastructural analysis under a Zeiss 10C transmission electron microscope.

\section{MORPHOMETRIC STUDIES}

Quantitative morphometry for the different parameters was performed using an automatic interactive analysis system IBAS-II, Kontron, Munich, Germany. Morphometric measurements were performed by one of the authors (RC) without knowledge of diet grouping. Microscopical views of the different mucosa areas for each section (duodenum, jejunum, and ileum) and for each animal were recorded on a video tape and transferred to the analyser image memory for the corresponding measurements. Measurements of villous height (from the tip of the villi to the villous crypt junction) and crypt depth (from the villous crypt junction to the lower limit of the crypt) were recorded as the mean of 15 fields for each specimen. Only vertically oriented villi and crypts were measured and the results were expressed in micrometers. Microvilli surface area per animal was assessed in two dimensions by multiplying the mean microvillous height by the mean microvilli perimeter. Microvilli perimeter was calculated from the diameter of villi from villi transections.

Lymphocyte infiltration as determined by the number of intraepithelial lymphocytes and the number of goblet cells was measured under the light microscopy on $200 \mu \mathrm{m}$ transections to the intestinal axis of villi and expressed as number of cells per $200 \mu \mathrm{m}$.

\section{STATISTICAL ANALYSIS}

After testing for homogenicity of variances using Levene's test, mean differences between the control and lactose groups were tested by unpaired Student $t$ tests and mean differences 
among control-control, control-nucleotide, lactose-control, and lactose-nucleotide groups using a one way analysis of variance and a posteriori Newman-Keuls multiple range test for specific comparison of means. ${ }^{22}$

\section{Results}

HISTOLOGICAL CHANGES IN THE SMALL INTESTINAL EPITHELIUM OF RATS WITH PROTRACTED DIARRHOEA

Scanning electron microscopy views recorded a disarray of intestinal villous structure in rats of the lactose group. Mucosal specimens showed mild to moderate villous atrophy with
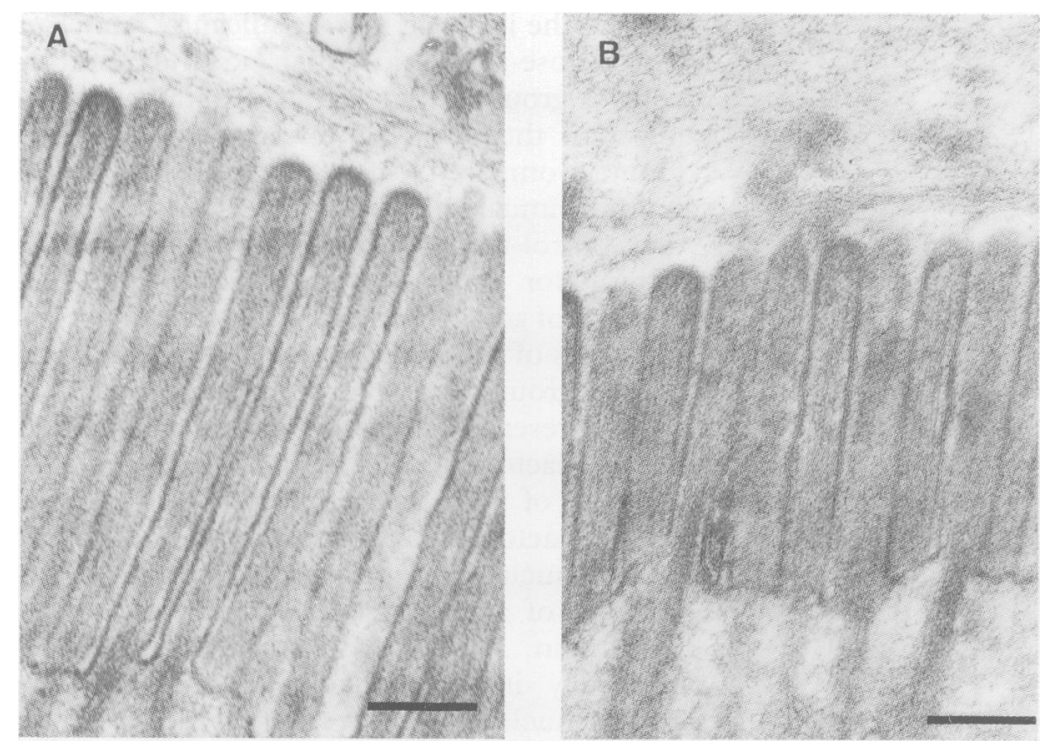

Figure 4: Transmission electron microscopy images of jejunum enterocyte microvilli from weaned rats fed a control semipurified diet $(A)$ and from weaned rats fed a lactose enriched diet that caused protracted diarrhoea $(B)$. (A): Microvilli are uniform in length and width. (B): microvilli are also uniform and regular in shape but are significantly shorter than in (A). Bar: $0.25 \mu \mathrm{m}$ (original magnification $\times 75000$ ).
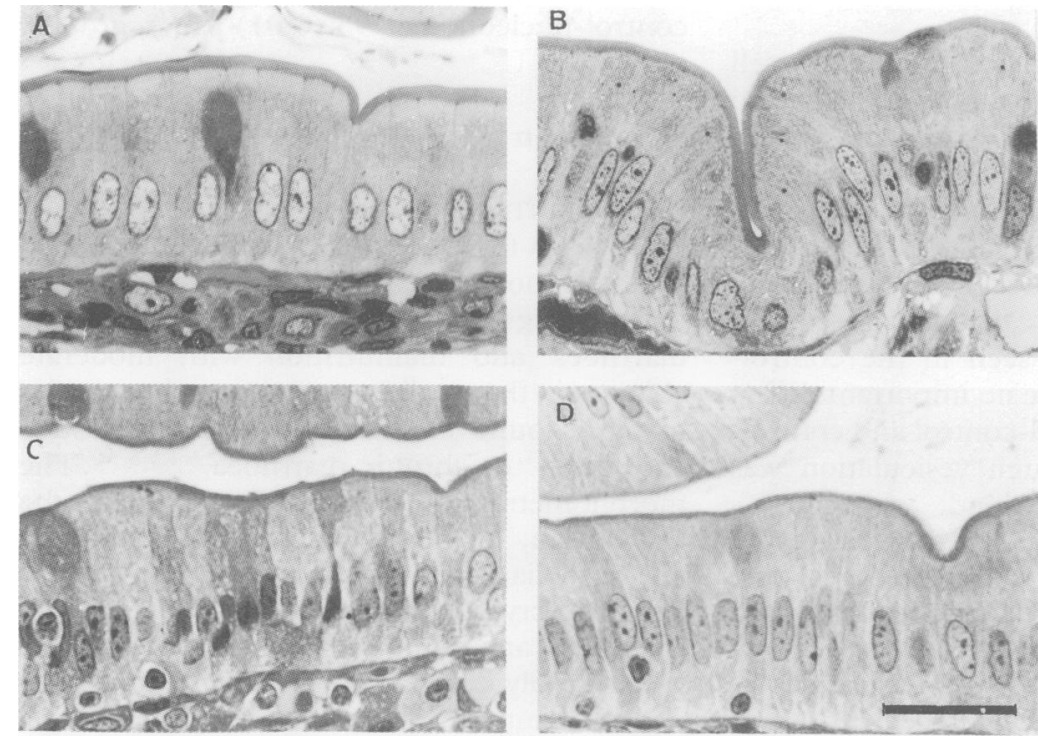

Figure 5: Light microscopy of duodenal epithelium from weaned rats fed a control diet $(A)$, the same diet supplemented with nucleotides $(B)$, and from weaned rats who recovered from protracted diarrhoea with the control diet $(C)$, and the same diet supplemented with 250 mg of nucleotides per $100 \mathrm{~g}$ of diet (D). Rats in group (C) still show some cytoplasmic vesiculation, which is not apparent in (D), and a higher number of intraepithelial lymphocytes than in (D). Bar: $25 \mu \mathrm{m}$ (original magnification $\times 850$ ).
TABLE II Effect of protracted diarrhoea induced by a lactose enriched diet on the morphometry of the small intestine in weanling rats

\begin{tabular}{|c|c|c|}
\hline & Control & Diarrhoea \\
\hline \multicolumn{3}{|c|}{ Villous height/crypt depth ratio: } \\
\hline Duodenum & $3.02(0.01)$ & $1.79(0.01)^{\star}$ \\
\hline Jejunum & $5.62(0.01)$ & $2 \cdot 27(0.01)^{\star}$ \\
\hline Ileum & $4.78(0.01)$ & $1 \cdot 74(0.01)^{\star}$ \\
\hline \multicolumn{3}{|c|}{ Number of goblet cells per $200 \mu \mathrm{m}$ length of mucosa: } \\
\hline Duodenum & $3.21(0.02)$ & $2.46(0.02)^{\star}$ \\
\hline Jejunum & $3.59(0.02)$ & $2.62(0.02)^{\star}$ \\
\hline Ileum & $3.27(0.02)$ & $2.59(0.02)^{\star}$ \\
\hline \multicolumn{3}{|c|}{ Number of intraepithelial lymphocytes per $200 \mu \mathrm{m}$ of mucosa: } \\
\hline Duodenum & $3.3(0.03)$ & $6.4(0.04)^{\star}$ \\
\hline Jejunum & $3.7(0.02)$ & $6.9(0.03)^{\star}$ \\
\hline Ileum & $4 \cdot 1(0 \cdot 01)$ & $7 \cdot 1(0 \cdot 02)^{\star}$ \\
\hline
\end{tabular}

Results are expressed as mean (SEM). The number of rats for each control and lactose groups were six. ${ }^{\star}$ Statistically significant $\mathrm{p}<0.001$ with respect to control group.

a patchy appearance characterised by extended regions with loss of microvilli and an unprecise delimitation of cell borders (Fig 1). The light microscopy study showed that villous height was reduced and crypts were elongated. Semithin sections of intestinal specimens showed a substantial infiltration of lymphocytes into the epithelium of the three segments duodenum, jejunum, and ileum. Moreover, the cytoplasm of enterocytes seemed uniformly vesiculated. A decreased number of goblet cells was seen compared with control animals and the enterocytes frequently showed lysis (Fig 2). Ultrastructural changes occurred in practically all of the intestinal fragments analysed for the lactose group although the intensity of these changes varied considerably. Transmission electron microscopy micrographs of the enterocyte cytoplasm showed enlarged and low inner density mitochondria, which showed few cristae. A dilated endoplasmic reticulum and Golgi apparatus as well as multivesicular bodies were seen (Fig 3). The microvilli of the enterocytes were usually shorter than normal but their architecture was well preserved and tufting and cupping was usually absent (Fig 4). Table II provides a summary of the morphometry data for duodenum, jejunum, and ileum for the lactose and control group. The intestinal villi of weaning rats with chronic diarrhoea had significantly lower villous height to crypt depth ratios than those of the control group in the three intestinal segments $(p<0.001)$. In addition the lactose group showed a significantly reduced number of goblet cells and an increased number of intraepithelial lymphocytes compared with the control group $(\mathrm{p}<0.001)$. The mean (SEM) surface area of microvilli for the entire small intestine was reduced in the lactose group compared with the control group $\left(1.75(0.01) \quad v \quad 1.82(0.01) \quad \mu^{2}\right.$, $\mathrm{p}<0 \cdot 01)$.

EFFECT OF DIETARY NUCLEOTIDES ON THE RECOVERY OF THE SMALL INTESTINE INJURED BY CHRONIC DIARRHOEA

Refeeding of weanling rats after chronic diarrhoea during four weeks with either a semipurified standard diet or the nucleotide supplemented diet resulted in a returning to normal of the images obtained by scanning electron 

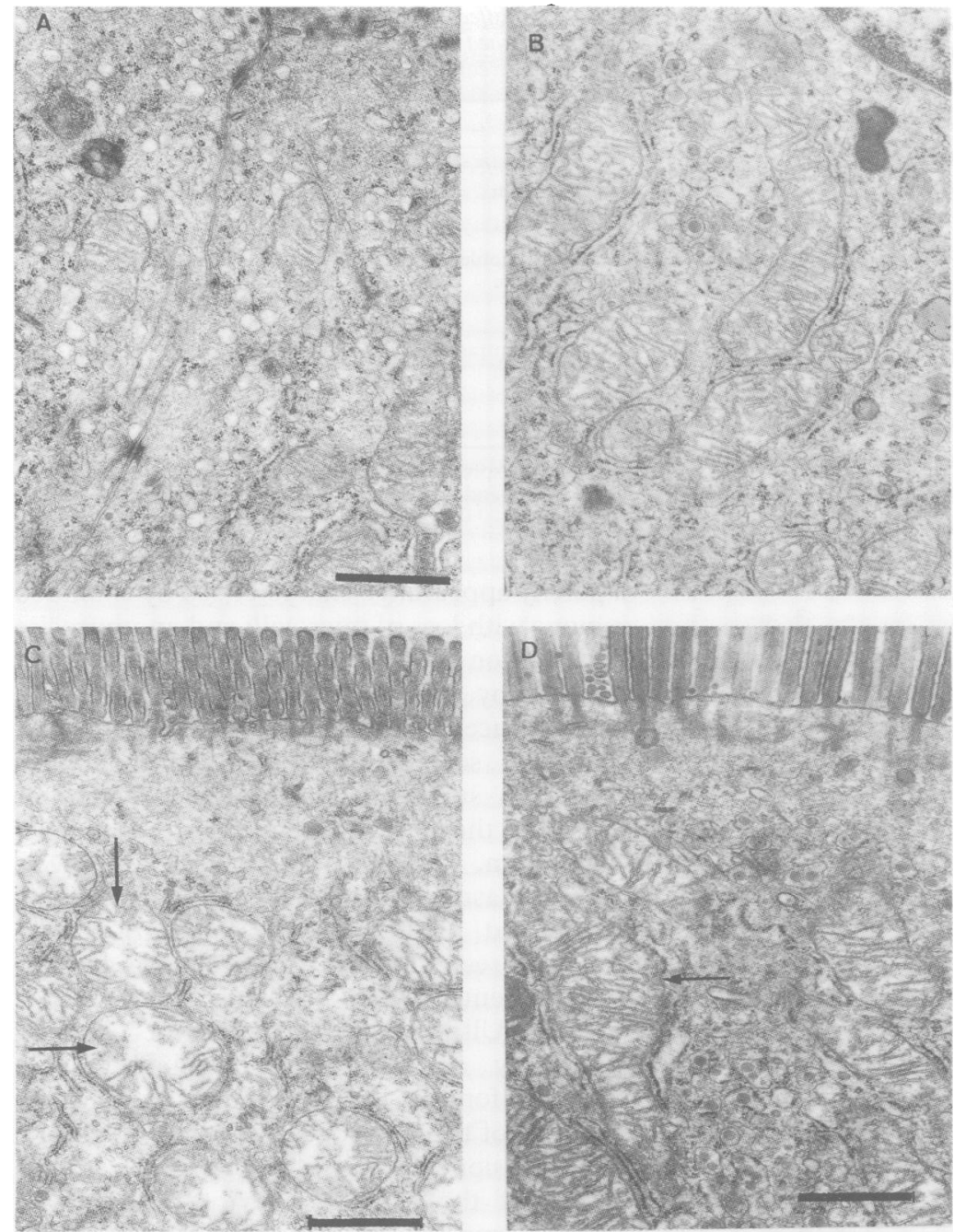

Figure 6: Electron micrographs of enterocyte cytoplasm from weaned rats fed a control diet $(A)$, the same diet supplemented with nucleotides $(B)$, and from weaned rats who recovered from protracted diarrhoea with the control diet $(C)$, and the same diet supplemented with $250 \mathrm{mg}$ of nucleotides per $100 \mathrm{~g}$ of diet (D). Rats in group controlcontrol $(A)$ showed a higher vesiculation than control-nucleotide group (B). Animals in $C$ still show a changed mitochondria, which shows a low matrix density and few cristae (arrows), whereas animals who recovered with the supplemented nucleotide diet show normal mitochondria, with dense matrix and well developed cristae. Bar: 1 um (original magnification $\times 30000$ ). control-control group, however, in the second group cytoplasm vesiculation was apparent and more noticeable than in the lactosenucleotide and control-nucleotide groups (Fig 6). Nevertheless, both lactose-control and lactose-nucleotide groups as well as controlcontrol and control-nucleotide groups showed uniform microvilli, regular in shape and of the same size (Fig 7). Table III shows the result of the small intestinal morphometry for lactosecontrol, lactose-nucleotide, control-control, and control-nucleotide groups. The villous height to crypt depth ratio was found to be significantly decreased for the three intestinal segments in the lactose-control group compared with the lactose-nucleotide, controlcontrol, and control-nucleotide groups $(p<0.001)$. The villous height/crypt depth ratio in the jejunum was significantly higher in the lactose-nucleotide than in the controlcontrol group; conversely this parameter was lower in the ileum of the lactose-nucleotide group compared with the control-control group. Similar differences were seen between the control-nucleotide and lactose-nucleotide groups for both jejunum and ileum. The number of goblet cells was reduced in the three segments of the small intestine for the lactosecontrol group compared with the other groups, which presented similar values. Weanling rats of the lactose-control group had a higher number of intraepithelial lymphocytes than those in lactose-nucleotide, control-control, and control-nucleotide groups; the lowest concentrations of intraepithelial lymphocytes were found in the control-nucleotide group, especially in the jejunum and ileum; the lactose-nucleotide group presented not only a lower number of intraepithelial lymphocytes than the lactose-control group but also than the control-control group. Moreover, the mean (SEM) surface area of microvilli was significantly lower in lactose-control $(1.67(0.01)$ $\left.\mu \mathrm{m}^{2}\right)$ than in lactose-nucleotide $(1.95(0.01)$ $\left.\mu \mathrm{m}^{2}\right)$, control-control $\left(1.90(0.02) \mu \mathrm{m}^{2}\right)$, and control-nucleotide $\left(1.93(0.01) \mu \mathrm{m}^{2}\right)$, groups.

microscopy; the enterocytes showed cell borders with well developed microvilli and convex apical surface. Light micrographs, however, still showed evidence of cytoplasmic vesiculation in the lactose-control group, which was not evident in the lactosenucleotide group. Although cytoplasmic vesiculation was larger in the lactose-control group, it could also be seen in the controlcontrol group. There were no important differences between the control-control and controlnucleotide groups although vesiculation was practically absent in the second.

Moreover, rats who recovered when treated with the nucleotide supplemented diet presented less intraepithelial lymphocytes than the lactose-control group (Fig 5). Transmission electron microscopy micrographs showed that in animals who recovered when treated with the control diet mitochondria remained changed in comparison with those animals fed on the nucleotide supplemented diet. Control-nucleotide animals showed a similar mitochondrial structure to those of the

\section{Discussion}

\section{EXPERIMENTAL MODEL OF PROTRACTED}

\section{DIARRHOEA IN WEANLING RATS}

We have shown that a lactose enriched diet fed to weanling rats for 14 days induced chronic diarrhoea and malnutrition with moderate changes in the small intestinal structure similar to those found in children with acute gastroenteritis $^{223}$ or chronic diarrhoea. ${ }^{1458-10}$ The morphometric studies performed on the duodenum, jejunum, and ileum of rats with chronic diarrhoea showed that the villous height to crypt depth ratio, the surface area of microvilli, and the number of goblet cells were considerably reduced in comparison with control animals. Moreover, a small bowel inflammatory response characterised by an increase in the number of intraepithelial lymphocytes was seen. The mucosal lesions had a patchy appearance as assessed by scanning electron microscopy and the mitochondrial 

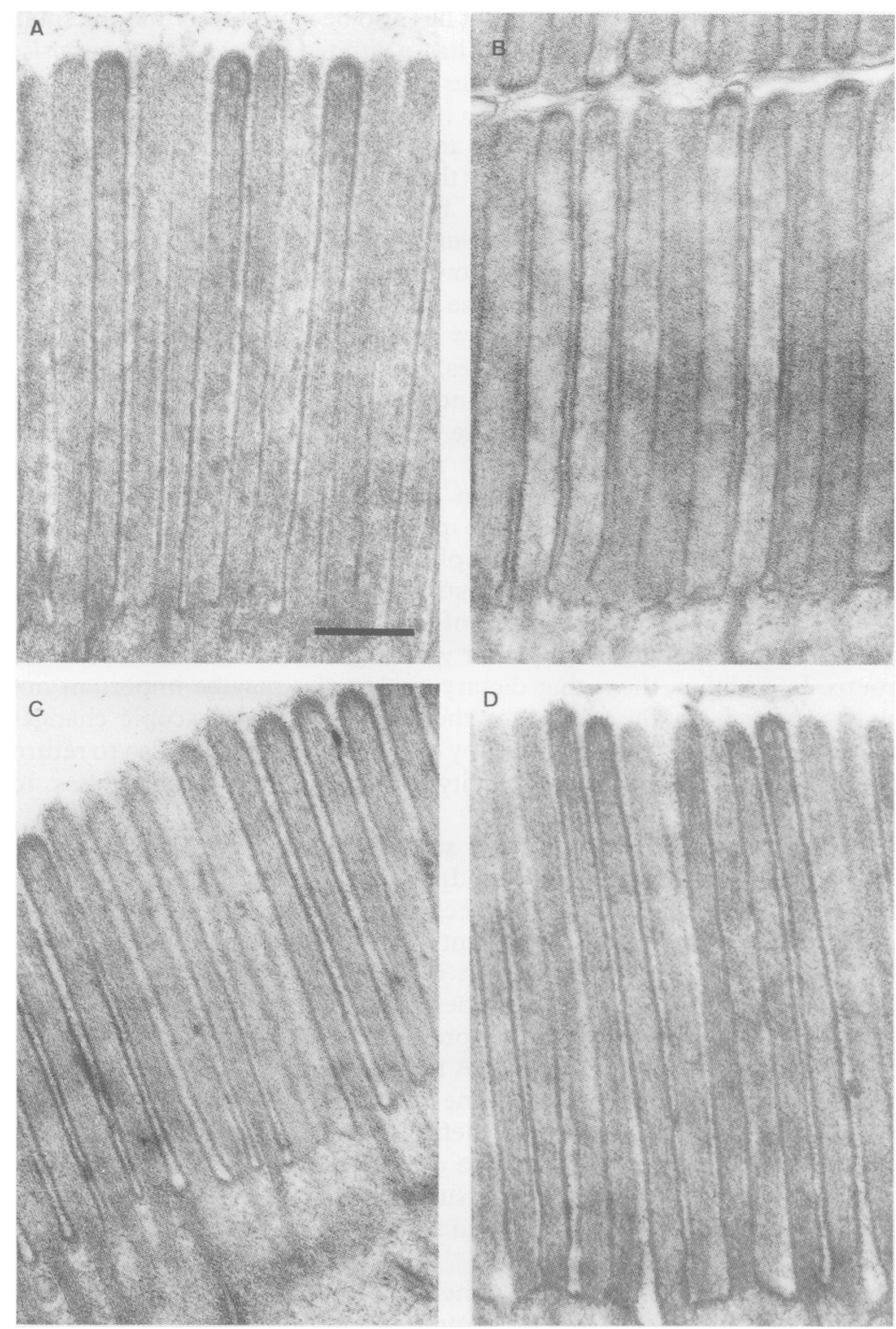

Figure 7: Electron micrographs of jejunum enterocyte microvilli from weaned rats fed a control semipurified diet $(A)$, the same diet supplemented with nucleotides $(B)$, and from weaned rats who recovered from protracted diarrhoea with the control diet (C), and the same diet supplemented with $250 \mathrm{mg}$ of nucleotides per $100 \mathrm{~g}$ of diet (D). All animals show uniform microvilli regular in shape and well developed glicocalix. Bar: $0.25 \mu \mathrm{m}$ (original magnification $\times 75$ 000). could not detect adherent bacteria in our specimens from animals suffering chronic diarrhoea particularly in the duodenum and jejunum. In ileum sections, however, we saw bacteria near the luminal surface. We consider that the changes seen in the weanling rats with protracted diarrhoea may result, at least in part, from nutrient malabsorption caused by osmotic diarrhoea, which leads to malnutrition. We have previously reported that the protein and DNA contents of the gut as well as the segmental activities of disaccharidases are severely reduced in the experimental model with chronic diarrhoea, ${ }^{18}$ others have reported similar changes associated to malnutrition in both animals and children. ${ }^{11-13} 15$

The change in the mitochondria ultrastructure has been one of the most interesting cytopathic changes seen in this study. This was the cause of cytoplasmic vesiculation seen in semithin intestinal sections under light microscopy. Fagundes-Neto et al have seen in two infants with acute diarrhoea that many of the mitochondria seem to loose their inner matrix density and undergo a decrease in the number of cristae. ${ }^{23}$ The change in ultrastructure of mitochondria may contribute to the pathogenicity of diarrhoea because these organellae play a key part in cell metabolic processes such as respiration and tricarboxylic acid cycle, which generate intermediary compounds for a number of biosynthetic pathways.

The high number of intraepithelial lymphocytes found in weanling rats with protracted diarrhoea is possibly a consequence of an increased passage of macromolecules as has been reported in patients with gastroenteritis. ${ }^{25}$ Several authors have reported that diarrhoea and other intestinal diseases, namely cows' milk, protein intolerance, and coeliac disease are associated with an increased number of intraepithelial lymphocytes and an increased number of macromolecules. ${ }^{526-28}$ This has been related to an increased influx rate of lymphocytes across the basal laminae induced by the presence of macromolecules. ${ }^{29}$

In summary, the experimental model of chronic diarrhoea described in this study mimics the histological and functional changes seen in children with chronic diarrhoea. density and a decreased number of cristae, the endoplasmic reticulum and Golgi apparatus were dilated and numerous multivesicular bodies were apparent.

Zarling and Mobarhan have shown that severely diet restricted weanling rats have mucosal protein loss caused in part by reduced villous height. ${ }^{24}$ Shiner et al have recently shown that infants aged less than 3 months affected by chronic diarrhoea present partial to subtotal or total villous atrophy with considerable patchiness in all specimens analysed. ${ }^{5}$ These authors have also reported, through morphometric studies, that villous height is decreased and crypt length and mucosal thickness are increased in children with chronic diarrhoea suggesting that the presence of nonadhering and adhering bacteria in the gut may contribute to the structural changes. ${ }^{5} \mathrm{We}$
EFFECT OF DIETARY NUCLEOTIDES ON GUT REPAIR IN WEANLING RATS WITH CHRONIC DIARRHOEA

The feeding of weanling rats recovering from lactose induced diarrhoea with a nutritionally complete semipurified diet for one month resulted in an apparent normalisation of the intestine structure. The villous height to crypt depth ratio, the number of goblet cells, and the microvilli area remained decreased and the number of intraepithelial lymphocytes increased compared with the control-control group. Animals recovered from diarrhoea that received the diet supplemented with nucleotides showed increased villous height to crypt depth ratio, a higher number of goblet cells, and reduced number of intraepithelial lymphocytes 
TABLE III Effect of dietary nucleotides on the recovery of small intestinal morphometry in rats that had diarrhoea induced by a lactose enriched diet

\begin{tabular}{|c|c|c|c|c|}
\hline & $C C$ & $C N$ & $L C$ & $L N$ \\
\hline \multicolumn{5}{|c|}{ Villous height/crypt depth ratio $(\mathrm{h} / \mathrm{c})$ : } \\
\hline Duodenum & $3.82(0.03)$ & $3.84(0.03)$ & $3 \cdot 28(0.01) \neq \rrbracket$ & $3.74(0.01)+5$ \\
\hline Jejunum & $6.60(0.04)$ & $6.71(0.04)$ & $4.47(0.01) \neq \rrbracket$ & $6.90(0.02)+\bar{s}$ \\
\hline Ileum & $4.91(0.04)$ & $4.95(0.03)$ & $3.87(0.01) \ddagger$ & $4.58(0.01)+\widehat{s} \|$ \\
\hline \multicolumn{5}{|c|}{ Number of goblet cells per $200 \mu \mathrm{m}$ length of mucosa: } \\
\hline Duodenum & $3 \cdot 70(0.03)$ & $3.72(0.03)$ & $3.46(0.03) \neq \llbracket$ & $3.66(0.02) \dagger$ \\
\hline Jejunum & $4.02(0.02)$ & $4 \cdot 12(0.02)$ & $3.88(0.02) \neq 9$ & $4 \cdot 10(0.03) \dagger$ \\
\hline Ileum & $4.25(0.03)$ & $4.32(0.05)$ & $3.89(0.02) \ddagger$ & $4 \cdot 21(1.39) \dagger$ \\
\hline \multicolumn{5}{|c|}{ Number of intraepithelial lymphocytes per $200 \mu \mathrm{m}$ of mucosa: } \\
\hline Duodenum & $2.9(0.05)$ & $2 \cdot 5(0.02)^{\star}$ & $4 \cdot 0(0.03) \ddagger$ & $2 \cdot 4(0 \cdot 02)+\$ \|$ \\
\hline Jejunum & $3.7(0.02)$ & $3.5(0.03)^{\star}$ & $4 \cdot 1(0 \cdot 02) \neq$ & $3 \cdot 8(0 \cdot 02)+5$ \\
\hline Ileum & $3.9(0.02)$ & $3.7(0.01)$ & $4 \cdot 4(0.01) \ddagger$ & $3.9(0.01)+5$ \\
\hline
\end{tabular}

Results are expressed as mean (SEM). The number of rats for each of the CC, CN, LC, and $\mathrm{LN}$ groups were six. CC is the control group and $\mathrm{CN}$ the control group fed with the control nucleotide supplemented diet. LC and LN are groups that recovered from diarrhoea with a nucleotide supplemented diet. LC and $L N$ are groups that recovered from diarrhoea with a ${ }^{\star}$ Statistically significant $(\mathrm{p}<0.001)$ CN $v$ CC; $+(\mathrm{p}<0.001)$ LN $v$ LE; $\neq(\mathrm{p}<0.001)$ LC $v$ CC $\uparrow(\mathrm{p}<0.01) \mathrm{LN} v \mathrm{CN} ; \|(\mathrm{p}<0.001) \mathrm{LN} v \mathrm{CC} ; \uparrow(\mathrm{p}<0.001) \mathrm{LC} v \mathrm{CN}$.

than those from lactose-control group. Rats from the control-control group showed a higher vesiculation than both the lactose-nucleotide and control-nucleotide groups. In addition, the number of intraepithelial lymphocytes in the control-nucleotide group was significantly lower than in the control-control group. This suggests that dietary nucleotides may be important for intestinal healing after injury induced by chronic diarrhoea; moreover, dietary nucleotides seem to be necessary for the maintenance of a normal ultrastructure even in healthy animals.

Nucleotides are found in foods mainly as nucleic acids liberated by nucleases during the digestive processes. In other foods, particularly in milk, purine and pyrimidine derivatives may be in the form of free acid soluble nucleotides and nucleosides or as DNA and RNA within white cells. ${ }^{30-32}$

In recent years, dietary nucleotides have been shown to influence lipid metabolism and essential fatty acid conversion to their main long chain derivatives during the neonatal period. ${ }^{33} 34$ Nucleotides, mainly inosine, affect the dietary bioavailability of iron. ${ }^{35}$ Moreover, dietary purine and pyrimidine derivatives influence the lymphoproliferative response, which is mediated by $\mathrm{T}$ cells. ${ }^{36}$ Nucleotides and nucleosides given intravenously to hepatectomised rats have been shown to improve liver regeneration ${ }^{37}$ and nucleotides present in tissue hepatic cultures are incorporated into hepatocytes and hepatocarcinoma cells enhancing their growth. ${ }^{38}$

Nucleotides are partly absorbed in the gut as nucleosides through different mechanisms, including active transport ${ }^{39}$ and $\mathrm{Na}^{+}$cotransport, ${ }^{40}$ and incorporated into body tissues mainly the liver, spleen, bone marrow, and gut. ${ }^{4} 42$ Dietary nucleotides are possibly of special importance in the development and proliferation of tissues with a rapid cell turnover such as intestine, bone marrow, and lymphocytes. De novo purine nucleotide synthesis may not be enough to support an increased need for nucleic acids induced by accelerated growth such as that occurring after intestinal injury. LeLeiko et $a l^{43}$ have shown that the de novo purine biosynthesis in the small intestine of the rat is further reduced when purine and pyrimidines are present in the diet and it has also been reported that the small intestine has a limited capacity to synthesise nucleotides by the de novo pathway. ${ }^{44}$

Dietary nucleotides may serve as precursors of DNA and RNA in some rapidly growing tissues by the salvage pathway thus sparing the organism from the cost of their synthesis, especially under those conditions when subjects are fed a low protein diet. György et al ${ }^{45}$ showed an increase in the body weight of weanling rats fed a low protein diet supplemented with nucleotides. Moreover, radiolabelled nucleotides are incorporated into the rat intestine at a higher rate in weaned than in adult animals. ${ }^{46}$

Dietary nucleotides seem to regulate the expression of salvage enzymes hypoxanthineguanine phosphoribosyl transferase and adenine phosphoribosyl transferase in the small intestine of $\mathrm{rat}^{47}$ and may also modify the activities of intestinal disaccharidases immediately after weaning. ${ }^{17}$ We have recently shown that dietary nucleotides may be important not only for the recovery of microscopic changes induced by chronic diarrhoea but also to return the activity of intestinal disaccharidases to normal. ${ }^{18}$

In this study a rapid normalisation of the mitochondria ultrastructure was seen in animals recovered from diarrhoea by feeding a supplemented nucleotide diet. As mitochondria DNA is independent from nuclear DNA we hypothesised that dietary nucleotides might serve as preformed precursors for mitochondrial DNA thus enhancing rapid normalisation of intestine structure and function. The fact that a deficient nucleotide diet results in enterocyte cytoplasmic vesiculation in healthy animals suggests that nucleotide may be considered as 'semi-essential' nutrients for the intestine.

In conclusion, dietary nucleotides are possibly important for the growth and development of the small intestine as well as for the repair of the intestine after chronic diarrhoea. Further studies in experimental animals and in children are needed to better evaluate the influence of those compounds on tissue growth and to ascertain the molecular mechanisms by which they act.

1 Greene HL, McCabe DR, Merenstein GB. Protracted diarrhea and malnutrition in infancy: changes in intestina morphology and disaccharidase activities during treatment with total intravenous nutrition or oral elemental diets. F Pediatr 1975; 87: 695-704.

2 Brunser $\mathrm{O}$, Castillo $\mathrm{C}$, Araya $M$. Fine structure of the small intestinal mucosa in infantile marasmic malnutrition. Gastroenterology 1976; 70: 495-507.

3 Lebenthal E. Devastating effects of chronic diarrhea in childhood. In: Lebenthal E, ed. Chronic diarrhea in children. New York: Raven E, ed. Chronic

4 Fagundes-Neto U, Wehba J, Viaro T, Machado NI Patricio FRS. Protracted diarrhea in infancy: clinical Patricio FRS. Protracted diarrhea in infancy: clinical aspects and ultrastructural analysis of the small

5 Shiner M, Putman M, Nichols VN, Nichols BL. Pathogenesis of small-intestinal mucosal lesions in chronic diarrhea of infancy: I. A light microscopic study. $\mathcal{F}$ Pediatr Gastroenterol Nutr 1990; 11: 464-80.

6 Barnes GL, Bishop RF, Townley RRW. Microbial flora and disaccharidase depression in infantile gastroenteritis. Acto Paediatr Scand 1974; 63: 423-6.

7 Calvin RT, Klish WJ, Nichols BL. Disaccharidase activity, jejunal morphology and carbohydrate tolerance in children with chronic diarrhea. 7 Pediatr Gastroenterol Nutr 1985; 4: 949-53.

8 Brunser O, Araya M. Damage and repair of small intestinal mucosa in acute and chronic diarrhea. In: Lebenthal $\mathrm{E}$, ed. Chronic diarrhea in children. New York: Raven Press, 1984: 31-55. 
9 Shiner M, Nichols VN, Barrish JP, Nichols BL. Pathogenesis of small-intestinal mucosal lesions in chronic diarrhea of infancy: II. An electron microscopic study. F Pediatr Gastroenterol Nutr 1990; 11: 464-80.

10 Poley JR. Ultrastructural topography of small bowel mucosa in chronic diarrhea in infants and children: investigations with the scanning electron microscope. In: Lebenthal E, ed. Chronic diarrhea in children. New York: Raven Press, ed. Chronic dia

11 Guiraldes E, Hamilton RJ. Effect of chronic malnutrition on intestinal structure, epithelial renewal, and enzymes in suckling rats. Pediatr Res 1981; 15: 930-4.

12 Firmansyah A, Suwandito L, Penn D, Lebenthal E. Biochemical and morphological changes in the digestive tract of rats after prenatal and postnatal malnutrition. $\mathrm{Am}$ tract of rats after prenatal and

13 Castillo RO, Pittler A, Costa F. Intestinal maturation in the rat: the role of enteral nutrients. FPEN 1988; 12: 490-5.

14 Altmann GG. Influence of starvation and refeeding on the mucosal size and epithelial renewal in the rat small intestine. Am 7 Anat 1972; 133: 391-400.

15 Butzner JD, Gall DG. Impact of refeeding on intestinal development and function in infant rabbits subjected to protein-energy malnutrition. Pediatr Res 1990; 27: 245-51.

16 Buts JP, Nyakabasa M. Role of dietary protein to adaptation at weaning in the development of the rat gastrointestinal tract. Pediatr Res 1985; 19: 857-62.

17 Uauy R, Stringel G, Thomas R, Quan R. Effect of dietary nucleosides on growth and maturation of the developing gut in the rat. $\mathcal{F}$ Pediatr Gastroenterol Nutr 1990; 10: gut in the $497-503$.

18 Núñez MC, Ayudarte MV, Morales D, Suárez MD, Gil A. Effect of dietary nucleotides on intestinal repair in rats with experimental chronic diarrhea. $\mathcal{} P E N$ 1990; 14: 598-604

19 Anderson TF. Techniques for the preservation of three dimensional structure in preparing specimens for the electron microscope. Trans NY Acad Sci 1969; 13: 130-4.

20 Spurr AR. A low viscosity epoxy resin embedding. $\mathcal{F}$ Ultrastruct Res 1969; 26: 31-43.

21 Reynolds ES. The use of lead citrate at high $\mathrm{pH}$ as an electron - opaque stain in electron microscopy. $\mathcal{f}$ Cell Biol 1963; 17: 208-12.

22 Dixon WJ, Brown MB, Engelman L, Jennrich RI. BMDP statistical software manual. Berkeley: University of California Press, 1990.

23 Fagundes-Neto U, Pontes-Pacheco I, Reis da Silva F, Wehba J. Ultrastructural study of alterations in the small intestinal epithelium of children with acute diarrhea. $\mathcal{f}$ Pediatr Gastroenterol Nutr 1984; 3: 510-5.

24 Zarling EJ, Mobarhan S. Effect of restricting a balanced diet on rat intestinal disaccharidase activity and intestinal architecture. F Lab Clin Med 1987; 109: 556-9.

25 Gruskay F, Cooke R. The gastrointestinal absorption of unaltered protein in normal infants and in infants recovering from diarrhea. Pediatrics 1955; 16: 763-8.

26 Penna FJ, Hill ID, Kingston D, Robertson K, Slavin G, Shiner $M$. Jejunal mucosal morphometry in children with and without gut symptoms and in normal adults. $f$ Clin Pathol 1981; 34: 386-92.

27 Shiner M, Ballard J, Brook CGD, Herman S. Intestinal biopsy in the diagnosis of cow's milk protein intolerance without acute symptoms. Lancet 1975; ii: 1060-3.

28 Zaitoun A, Record CO. Morphometric studies in duodenal biopsed form patients with coeliac disease: the effect of the steroid fluticasone propionate. Aliment Pharmacol Therap 1991; 5: 151-60

29 Marsh MN. Studies of intestinal lymphoid tissue. III. Quantitative analysis of epithelial lymphocytes in the small intestine of human control subjects and of patients with coeliac sprue. Gastroenterology 1980; 79: 481-92.

30 Kobata A, Ziro S, Kida M. The acid-soluble nucleotides of milk. I. Quantitative and qualitative differences of nucleotide constituents in human and cow's milk. $\mathscr{f}$ nucleotide constituents in
Biochem 1962; 51: 277-87.

31 Gil A, Sánchez-Medina F. Acid-soluble nucleotides of human milk at different stages of lactation. $\mathcal{f}$ Dairy Res 1982; 49: 301-4

32 Janas LM, Picciano MF. The nucleotide profile of human milk. Paediatr Res 1982; 16: 659-62.

33 Sánchez-Pozo A, Pita ML, Martínez A, Molina JA, Sánchez-Medina F, Gil A. Effects of dietary nucleotides upon lipoprotein pattern of newborn infants. Nutr Res 1986; 6: 763-71.

34 Gil A, Pita ML, Martínez A, Molina JA, Sánchez-Medina F. Effects of dietary nucleotides on the plasma fatty acids in at-term neonates. Hum Nutr Clin Nutr 1986; 40C: 185-95.

35 Faelli A, Esposito G. Effect of inosine and its metabolites in intestinal iron absorption in the rat. Biochem Pharmacol 1970; 19: 2551-4.

36 Frederick B, Rudolph FB, Fanslow WC, Anil D, Kulkarni $\mathrm{AD}$, Van Buren CT. Effect of dietary nucleotides on lymphocyte maturation. Pediatr Res 1985; 19: 773-8.

37 Ogoshi S, Iwasa M, Yonezawa T. Effect of nucleotide and nucleoside mixture on rats given total parenteral nutrition after 70\% hepatectomy. IPEN 1985; 9: 339-42.

38 Ohyanagi H, Nishimatsu S, Kanbara Y, Usami M, Saitoh Y. Effects of nucleosides and nucleotides on DNA synthesis by the salvage and the novo pathway in primary monolayer cultures of hepatocytes and hepatomic cells. $\mathscr{T P E N}$ 1989; 13: 51-8.

39 Harms VH, Stirling CE. Transport of purine nucleosides and nucleosides by 'in vitro' rabbit ileum. Am 7 Physiol and nucleosides by

40 Schanker KS, Tocco DJ. Active transport of some pyrimidines across the rat intestinal epithelium. f Pharmacol Expt Ther 1960; 128: 115-21.

41 Sonoda T, Tatibana M. Metabolic fate pyrimidines and purines in dietary nucleic acids ingested by mice. Biochim Biophys Acta 1978; 521: 55-66.

42 Savaiano DA, Clifford AJ. Absorption, tissue incorporation and excretion of free-purine bases in rat. Nutrition Reports International 1978; 17: 551-6.

43 LeLeiko NS, Bronstein AD, Baliga S, Munro NH. De novo purine nucleotide synthesis in the rat small and large purine nucleotide synthesis in the rat small and large intestine: effect of dietary protein
Gastroenterol Nutr 1983; 2: 313-9.

44 LeLeiko NS, Bronstein AD, Munro NH. Effect of dietary purines on the novo synthesis of purine nucleotides in the purines on the novo synthesis of purine nucleotides in

45 György P. Biochemical aspects of human milk. Am $\mathscr{f}$ Clin Nutr 1971; 24: 970-5.

46 Kubota A. Nutritional study of nucleotide components in the milk. Acta Paediatr fpn 1969; 73: 197-209.

47 LeLeiko NS, Martin BA, Walsh M, Kazlow P, Rabinowitz $\mathrm{S}$, Sterling K. Tissue-specific gene expression results from a purine- and pyrimidine-free diet and 6-mercaptopurine in the rat small intestine and colon. Gastroenterology 1987; 93: $1014-20$. 